Check for updates

Cite this: RSC Adv., 2018, 8, 1361

\title{
Lignin-first depolymerization of native corn stover with an unsupported $\mathrm{MoS}_{2}$ catalyst $\uparrow$
}

\author{
Song Li, abcd Wenzhi Li, (D) *e Qi Zhang, (D) *abc Riyang Shu, ${ }^{\text {abc }}$ Huizhen Wang, \\ Haosheng $\mathrm{Xin}^{\mathrm{e}}$ and Longlong $\mathrm{Ma}^{\mathrm{abc}}$
}

The lignin-first biorefinery method appears to be an attractive approach to produce phenolic chemicals. Herein, corn stover was employed for the production of phenolic monomers using an unsupported nonnoble $\mathrm{MoS}_{2}$ catalyst. The yield of phenolic monomers was enhanced from $6.65 \%$ to $18.47 \%$ with $\mathrm{MoS}_{2}$ at $250{ }^{\circ} \mathrm{C}$ and about $75 \%$ lignin was degraded with more than $90 \%$ glucan reserved in the solid residues. The Fourier-Transform Infrared (FT-IR) and heteronuclear single quantum coherence-nuclear magnetic resonance $\left({ }^{1} \mathrm{H}-{ }^{13} \mathrm{C}\right.$ HSQC-NMR) characterization suggested that the cleavage of the $\beta$-O- $4, \gamma$-ester and benzyl ether linkages were enhanced, promoting the delignification and the depolymerization of lignin. The catalyst performance was relatively effective with $14.30 \%$ phenolic monomer yield after the fifth run. The effects of the reaction temperature, the initial hydrogen pressure, the dosage of catalyst, and the reaction time were investigated. The model reactions were also proposed for the potential mechanism study. This work provides some basic information for the improvement of the graminaceous plant ligninfirst process with a non-noble metal catalyst.

Received 30th October 2017 Accepted 18th December 2017

DOI: $10.1039 / c 7 r a 11947 j$

rsc.li/rsc-advances linked by different ether bonds and carbon-carbon bonds, including $\beta-\mathrm{O}-4, \beta-5, \beta-\beta$, and $\beta-1$ linkages, of which more than half of the linkage structures are $\beta-O-4$ linkages. ${ }^{4}$ Furthermore, lignin is cross-linked with carbohydrates in the plant cells and the middle lamella. ${ }^{7}$ The complex chemical and physical structure of lignin makes it difficult to depolymerize lignin for biochemicals and biofuels. To develop the effective depolymerization methods, the crucial tasks are to destroy the physical structure of lignin and break the chemical bonds between different units.

This is the prevalent strategy for lignin upgradation by reductive depolymerization with metal catalysts. ${ }^{\mathbf{8 9}}$ Moreover, recent advances have been reported with different lignin sources. Noble metal catalysts, such as $\mathrm{Ru} / \mathrm{C}, \mathrm{Pd} / \mathrm{C}, \mathrm{Pt} / \mathrm{C}$, and $\mathrm{Rh} /$ $\mathrm{C}^{\mathbf{1 0 - 1 2}}$ and non-noble transition metal sulfide, carbide, and nitride catalysts, such as sulfided NiMo and CoMo, $\mathrm{MoC}_{2}$, and TiN, ${ }^{13-15}$ were introduced in the depolymerization of technical lignin. The active metals played an important role in the cleavage of the $\beta$-O-4 linkage through hydrogenation or hydrodeoxygenation. Moreover, technical lignin, including lignosulfonate lignin, kraft lignin, organosolv lignin, and soda lignin, ${ }^{\mathbf{1 6}}$ is usually produced via pretreatments under various harsh conditions. The pretreatments dramatically lead to the structural changes by severe and irreversible condensation. In fact, the condensation, resulting from the transformation of the ether bonds into the relative stable carbon-carbon bonds during the pretreatments, makes the subsequent lignin depolymerization process harder. ${ }^{17}$ High temperature and char formation are also the common challenges in the process of
Guangzhou Institute of Energy Conversion, Chinese Academy of Sciences, Guan 510640, PR China. E-mail: zhangqi@ms.giec.ac.cn; Fax: +86 20 87057789; Tel: +86 20 ${ }^{b}$ CAS Key Laboratory of Renewable Energy, Guangzhou 510640, PR China ${ }^{c}$ Guangdong Provincial Key Laboratory of New and Renewable Energy Research and Development, Guangzhou 510640, PR China

${ }^{d}$ University of Chinese Academy of Sciences, Beijing 100049, PR China

${ }^{e}$ Laboratory of Basic Research in Biomass Conversion and Utilization, Department of Thermal Science and Energy Engineering, University of Science and Technology of China, Hefei 230026, PR China.E-mail: liwenzhi@ustc.edu.cn

$\dagger$ Electronic supplementary information (ESI) available. See DOI: $10.1039 / \mathrm{c} 7 \mathrm{ra} 11947 \mathrm{j}$ 
lignin-to-aromatic conversion. Herein, these drawbacks have seriously restricted the depolymerization of technical lignin into value-added chemicals and biofuels under relatively mild conditions. Compared with technical lignin, native lignin has $40-60 \%$ of total intermolecular linkages in the form of $\beta-\mathrm{O}-4$ ether bonds, ${ }^{16}$ which makes native lignin a better feedstock for lignin-to-aromatic conversion. Based on this, lignin-first as a novel concept has been put forward with native lignin to extract more valuable products from lignin. ${ }^{3}$ Lignin-first depolymerization focuses on prohibiting the lignin condensation and improving the efficiency of lignin-to-aromatic conversion. ${ }^{3,17}$ In the solvolysis process, the native lignin is extracted from biomass by organic solvents. The extracted lignin fragments are depolymerized into monomers and oligomers via a reductive pathway with a metal catalyst. In this process, the carbohydrate pulp is primarily retained in the solid residues, which can be used for producing valuable chemicals and biofuels. ${ }^{3,18,19}$ Numerous efforts have been made in the recent years. For instance, noble metal catalysts, such as $\mathrm{Ru} / \mathrm{C}, \mathrm{Pd} / \mathrm{C}, \mathrm{Pt} / \mathrm{C}$, and $\mathrm{Rh} / \mathrm{C}$, were employed for native birch. ${ }^{18,20,21}$ Furthermore, the synergistic effects of the noble metal catalysts were investigated at a relatively mild condition with an acid as a co-catalyst (such as $\mathrm{HCl}, \mathrm{Al}(\mathrm{OTf})_{3}$, and metal triflates). ${ }^{22}$ To reduce the catalyst cost, the Ni-based catalysts, such as $\mathrm{Ni} / \mathrm{Al}_{2} \mathrm{O}_{3}$ (ref. 23) and $\mathrm{Ni} / \mathrm{C},{ }^{19}$ were introduced in the process. Based on the previous studies, the lignin-first conversion approach exhibits a high yield and selectivity for the production of phenolic monomers. The reductive metal catalyst has been proven effective for the cleavage of the lignin-carbohydrate bonds and lignin-lignin ether bonds ${ }^{22,23}$ and the acids played a significant role as the co-catalyst. ${ }^{24,25}$

Compared to lignin with a high $\mathrm{S} / \mathrm{G}$ ratio from hardwoods, lignin of the graminaceous plants (e.g. corn stover) is more complex; there is a higher content of hydroxycinnamic acids, particularly $p$-coumaric acid (pCA) and ferulic acid (FA), which are ester-linked or ether-linked in the cell walls. ${ }^{26,27}$ However, only few studies have been conducted using lignin of graminaceous plants. For instance, $\mathrm{Ru} / \mathrm{C}, \mathrm{Ni} / \mathrm{C}$, and the synergistic effects with $\mathrm{H}_{3} \mathrm{PO}_{4}$ were studied with native corn stover as the feedstocks. ${ }^{24}$ Though the phenolic monomers were harvested, the recyclability of the catalyst was not reported. Thus, the investigation on the lignin-first process of the graminaceous plants will provide a lignin-first approach with a much wider applicability for the utilization of lignocellulose. On the whole, noble metal catalysts are high cost and the Ni-based catalysts confront with the limitation of the recyclability. Moreover, the chemocatalytic conversion of carbohydrate pulp mostly needs the involvement of acids. ${ }^{\mathbf{2 0 , 2 8 , 2 9}}$ Therefore, a non-noble metal catalyst capable of hydrogenation and acid tolerance is preferred for the lignin-first process.

$\mathrm{MoS}_{2}$ is a good choice for the lignin-first reductive depolymerization. It could tolerate some common acids except strong oxidative acids and is capable of hydrogenation (HYD), hydrodesulfurization (HDS), and hydrodeoxygenation (HDO). ${ }^{30,31}$ In addition, it has been reported that Ni-modified $\mathrm{MoS}_{2}$ catalyst was effective for the cleavage of $\beta-\mathrm{O}-4$ ether bond via a dehydroxylation-hydrogenation strategy; ${ }^{32}$ also, $\mathrm{MoS}_{2}$ has been introduced in the depolymerization of alkali lignin for bio-oil production. ${ }^{33}$ As a non-noble transition-metal sulfide catalyst, it can be easily hydrothermally synthesized by an easier method compared to the synthesis of supported NiMo or CoMo metal sulfide. The unsupported layered structure can offer more active sulphur vacancies at the edge of the slab.

In this study, the lignin-first biorefinery was further developed with the depolymerization of native corn stover lignin via a non-noble unsupported $\mathrm{MoS}_{2}$ catalyst in methanol. The effect of the reaction conditions, including the reaction temperature, the initial hydrogen pressure, the dosage of catalyst, and the reaction time, on the yield of the phenolic monomers and the liquid products were investigated in detail. In particular, FT-IR and ${ }^{1} \mathrm{H}-{ }^{13} \mathrm{C}$ HSQC-NMR techniques were utilized to perform the chemical characterization of the liquid products. The model reactions were proposed for the potential mechanism study in order to get a comprehensive understanding of the lignin-first process.

\section{Methods}

\subsection{Materials}

Corn stover was collected from Mengcheng City, Anhui Province of China. After being washed and dried at $60{ }^{\circ} \mathrm{C}$ for $48 \mathrm{~h}$, the stock was cut and milled. The corn stover fragments sieved through a 30-mesh screen were collected and sealed for later use after being dried in an oven at $105{ }^{\circ} \mathrm{C}$ for $6 \mathrm{~h}$. Hydrochloric acid (36-38\%), sulfuric acid (95-98\%), methanol, water-free ethanol, acetone, ammonium molybdate tetrahydrate, and thiourea were purchased from Sinopharm Chemical Reagent Co., Ltd. (Shanghai, China). Methyl sulfoxide-d6 (99.9\%) for NMR characterization was purchased from Aladdin (Shanghai, China). All chemicals were used without further purification.

\subsection{Synthesis and characterization of $\mathrm{MoS}_{2}$}

The method for the synthesis of $\mathrm{MoS}_{2}$ was referred to that reported of Wang et al. and Li et al. ${ }^{33,34}$ Specifically, $0.614 \mathrm{~g}$ ammonium molybdate tetrahydrate and $0.802 \mathrm{~g}$ thiourea were dissolved in $80 \mathrm{~mL}$ double distilled water via ultrasonication and then stirred for $10 \mathrm{~min}$. After the $\mathrm{pH}$ value was adjusted to 0.8-0.9 with hydrochloric acid under stirring, the solution was transferred into a $150 \mathrm{~mL}$ Teflon-lined stainless-steel autoclave and the reaction was carried out at $200{ }^{\circ} \mathrm{C}$ for $24 \mathrm{~h}$. The black products were collected and washed with acetone and water, in sequence, to remove the soluble matter. Finally, the ethanol washed $\mathrm{MoS}_{2}$ was dried at $60{ }^{\circ} \mathrm{C}$ for $12 \mathrm{~h}$ under vacuum.

The properties of the fresh and recycled catalysts were characterized using scanning electron microscope (SEM, FEI SIRION200), X-ray diffractometer (XRD, Rigaku SmartLab), Xray photoelectron spectrometer (XPS, Thermo-VG Scientific ESCALAB 250), Autosorb iQ Station (Quantachrome), and Autosorb-iQ-C (ASIQACIV200-2).

\subsection{Determination of carbohydrates and lignin}

The determination of carbohydrates and lignin were conducted according to the Laboratory Analytical Procedures (LAP) 
established by the National Renewable Energy Laboratory (NREL) and also according to the previous study reported by our group. ${ }^{35}$ The results are listed in Table $\mathrm{S} 1 . \dagger$

\subsection{Depolymerization of native corn stover lignin}

Typically, $0.300 \mathrm{~g} \mathrm{MoS}$, $2.000 \mathrm{~g}$ corn stover together with $40 \mathrm{~mL}$ methanol were sealed in a $100 \mathrm{~mL}$ autoclave made of Zirconium-702 (Anhui Kemi Machinery Technology Co., Ltd.). The autoclave was purged with $\mathrm{H}_{2}$ for three times and pressurized to 3.0 MPa with $\mathrm{H}_{2}$. A mechanical impeller speed was set at $800 \mathrm{rpm}$. The reaction temperature was raised from room temperature to $250{ }^{\circ} \mathrm{C}$ in $40 \mathrm{~min}$ and held for $2 \mathrm{~h}$. After the reaction was complete, the autoclave was cooled down to room temperature in water.

\subsection{Analysis of the products}

After the gas was released, the reaction mixture was filtered into two parts. The residue was washed with $30 \mathrm{~mL}$ methanol for three times before being dried at $80{ }^{\circ} \mathrm{C}$ overnight. The liquid part was reserved for monomer analysis, while the rest of the liquid products (LP) were evaporated using a rotary evaporator at $38{ }^{\circ} \mathrm{C}$ and then extracted with ethyl acetate. The evaporated ethyl acetate soluble products (EP) were defined as bio-oil.

Gas chromatography/mass spectrometry (GC-MS, Agilent 7890/5975) and gas chromatography (GC, SHIMADZU GC-2010) with flame-ionization detection were employed for qualitative and quantitative analysis of the phenolic monomers. Acetophenone was used as an internal standard. Fourier transform infrared spectrometry (FT-IR, Nicolet 8700) and nuclear magnetic resonance spectroscopy (NMR, Bruker AVANCE AV III 400) were utilized for further analysis of the chemical composition of the liquid products.

The volatile products were confirmed by GC-MS as follows: guaiacyl compounds, including 2-methoxy-4-propenylphenol, 2methoxy-4-ethylphenol, 2-methoxy-4-propylphenol, and methyl trans-4-hydroxy-3-methoxycinnamate (methyl ferulate, $\mathrm{MF}$ ); $p$ hydroxyphenyl compounds, including 4-ethylphenol, methyl trans-p-coumarate (MpC), and methyl 3-(4-hydroxyphenyl) propionate; syringyl compounds, including 2,6-dimethoxy-4propylphenol and 2,6-dimethoxy-4-allylphenol. In addition, 2,3-dihydrobenzofuran was detected. The yield of the products was calculated using the following equations:

$$
\begin{gathered}
Y_{\mathrm{Mi}}=M_{\mathrm{i}} / M_{\mathrm{L}} \times 100 \% \\
Y_{\mathrm{SumG}}=\mathrm{M}_{\mathrm{SumG}} / M_{\mathrm{L}} \times 100 \% \\
Y_{\mathrm{SumS}}=\mathrm{M}_{\mathrm{SumS}} / M_{\mathrm{L}} \times 100 \% \\
Y_{\mathrm{SumH}}=\mathrm{M}_{\mathrm{SumH}} / M_{\mathrm{L}} \times 100 \% \\
Y_{\mathrm{Sum}}=\mathrm{M}_{\mathrm{Sum}} / M_{\mathrm{L}} \times 100 \% \\
Y_{\mathrm{LP}}=\mathrm{M}_{\mathrm{LP}} / M \times 100 \% \\
Y_{\mathrm{EP}}=\mathrm{M}_{\mathrm{EP}} / M \times 100 \%
\end{gathered}
$$

$$
Y_{\mathrm{SR}}=\mathrm{M}_{\mathrm{SR}} / M \times 100 \%
$$

where $M_{\mathrm{i}}$ : the mass of monomer in the liquid products; $M_{\mathrm{L}}$ : the mass of native corn stover lignin; $M_{\text {SumG }}, M_{\text {Sums }}$, and $M_{\text {SumH }}$ : the sum mass of guaiacyl, syringyl, and $p$-hydroxyphenyl phenolic monomers in the liquid products; $M_{\text {Sum }}$ : the sum mass of all phenolic monomers in the liquid products; $M_{\mathrm{LP}}$ : the mass of the liquid products; $M_{\mathrm{EP}}$ : the mass of the extractive products; $M_{\mathrm{SR}}$ : the mass of the solid residual corn stover (SR); $M$ : the mass of corn stover; the mass of the residual corn stover was determined by subtracting the mass of the catalyst from the reaction residues.

\section{Results and discussion}

\subsection{Catalyst characterization}

The physical properties of the fresh catalyst were evaluated. As shown in Fig. 1a the XRD $2 \theta$ peaks at $13^{\circ}, 33^{\circ}$, and $57^{\circ}$ are in accordance with the (001), (100), and (110) lattice planes of $\mathrm{MoS}_{2}$ (JCPDS card no. 37-1492), respectively. The broad XRD reflection of $\mathrm{MoS}_{2}$ suggested that it might have an amorphous structure and the low degree of crystallinity could provide more active sulphur vacancies, which is critical for the catalytic reactivity. In addition, the XPS (Fig. 1b) results suggested that the atomic ratio of $S$ to Mo was $9: 4$. Thus, it can be speculated that most of the hydrothermal synthesized black powder was $\mathrm{MoS}_{2}$. In addition, the results from the nitrogen adsorption-desorption experiments revealed that $\mathrm{MoS}_{2}$ has a large Barrett-Joyner-Halenda (BJH) adsorption surface area of $68.831 \mathrm{~m}^{2} \mathrm{~g}^{-1}$, pore volume of 0.252 $\mathrm{cm}^{3} \mathrm{~g}^{-1}$, and a mesoporous pore diameter of $2.193 \mathrm{~nm}$, which is in accordance with the porous flower-like layer structure observed by SEM/TEM (Fig. 2). This structure ensured the frequent access of the substance to the active sites on the edge of the layered structure, which promoted the degradation of lignin and the generation of the phenolic monomers.

\subsection{Influence of the reaction conditions}

The depolymerization of native corn stover lignin was studied at various reaction conditions, including the reaction temperature, the initial hydrogen pressure, the dosage of catalyst, and
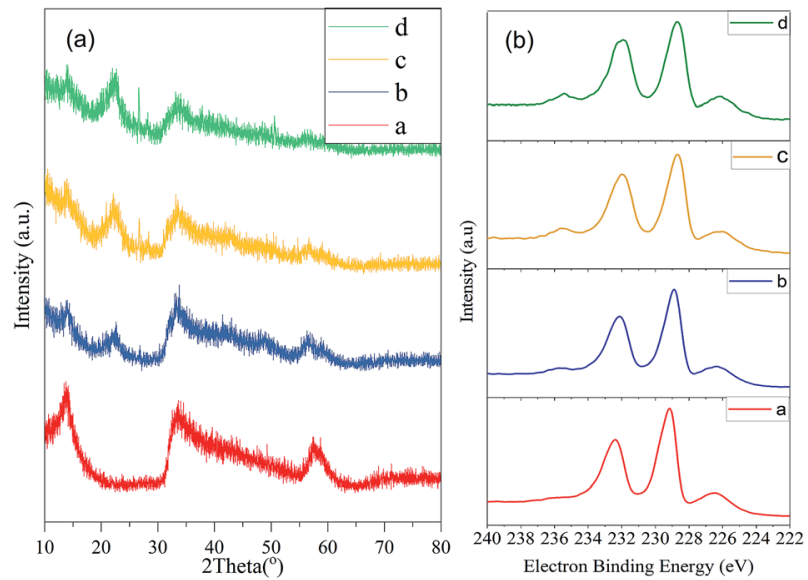

Fig. 1 XRD/XPS spectra of the $M_{2} S_{2}$ : (a) XRD and (b) XPS, a: fresh $\mathrm{MoS}_{2}$, b: used once, c: used 4 times, and d: used 5 times. 


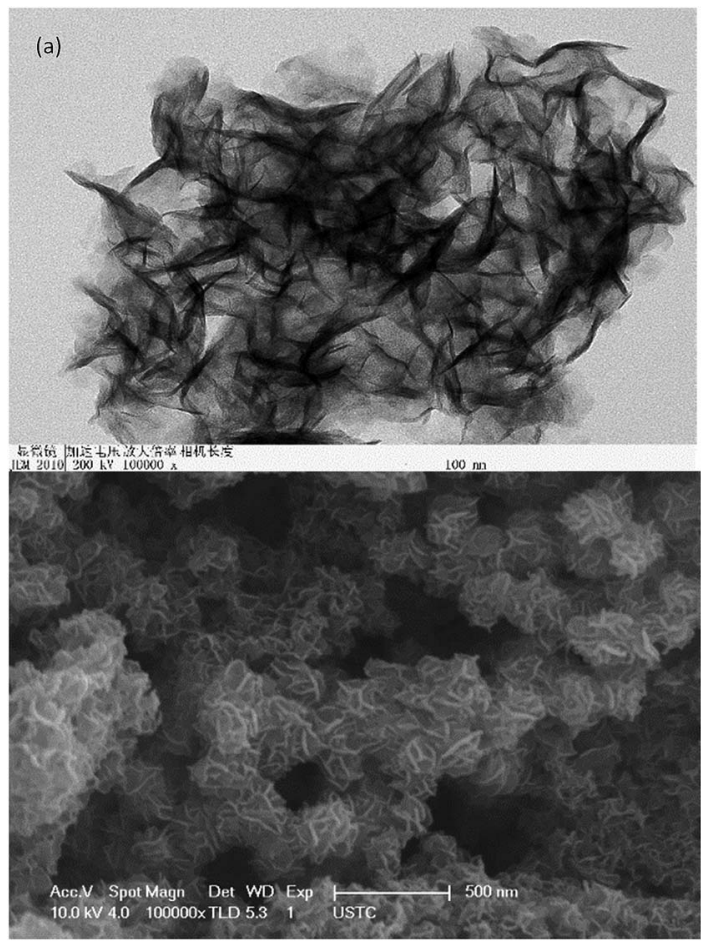

Fig. 2 TEM/SEM of $\mathrm{MOS}_{2}$ : (a) TEM and (b) SEM.

the reaction time. In particular, the maximum phenolic monomer yield was $19.18 \%\left(260{ }^{\circ} \mathrm{C}, 3 \mathrm{MPa} \mathrm{H}\right.$, $15 \mathrm{wt} \% \mathrm{MoS}_{2}, 2$ h) and the maximum EP yield was $34.80 \%\left(250{ }^{\circ} \mathrm{C}, 3 \mathrm{MPa}_{2}\right.$, $15 \mathrm{wt} \% \mathrm{MoS}_{2}$ ). Collectively, the LP, EP, and SR yields revealed the liquefaction degree of the corn stover, the depolymerization degree of lignin, and the sugar retention of the corn stover, respectively. The phenolic monomer yield was not only dependant on the delignification of the corn stover and the depolymerization of lignin, but was also affected by the HDO and repolymerization of the monomer products, which constantly occurred in competition with the lignin-first process. Moreover, the LP yield was beyond the total lignin content in corn stover $(21.10 \%)$, suggesting that not only lignin, but also the carbohydrate components were liquefied and that would be proven by the characterization of the liquid products and the chemical components analysis of the products.

The effect of the reaction temperature was significant on the lignin-first process as shown in Fig. 3 and Table 1. The LP yield was stable at around $38 \%$ at over $240{ }^{\circ} \mathrm{C}$, indicating that more volatile gas products were released. The yield of total phenolic monomers was changed from $16.69 \%$ to $19.18 \%$ as the temperature rose from $230{ }^{\circ} \mathrm{C}$ to $260{ }^{\circ} \mathrm{C}$ and slightly down to $16.79 \%$ when the temperature increased up to $270{ }^{\circ} \mathrm{C}$. This could be attributed to the increase of the depolymerization through the cleavage of the $\beta-\mathrm{O}-4$ linkages in supercritical methanol as the temperature increased up to $260^{\circ} \mathrm{C}$. Moreover, the repolymerization reactions might be more dominant as the reaction temperature increased from 260 to $270{ }^{\circ} \mathrm{C}$, resulting in the decline of the phenolic monomer yield. The decline in the yield of both guaiacols and $p$-hydroxyphenyl phenols was in accordance with this tendency, while the yield of syringols maintained at around $4 \%$. This change could be ascribed to the active opening at 5-position on the aromatic ring, which made the $\mathrm{G}$ and $\mathrm{H}$-type units prone to the repolymerization reactions at a higher temperature comparing with that for the S units. ${ }^{36,37}$

Therefore, the lignin fragments were constantly generated, resulting in the yield of EP to rise slowly. Moreover, the SR yield declined to $47.56 \%$, which was less than the sum of cellulose and hemicellulose (53.04\%), indicating that the degradation of the carbohydrate components occurred extensively with the increase in temperature.

Compared to that of the reaction temperature, the effect of the initial hydrogen pressure was much more significant on the lignin-first process as shown in Fig. 3 and Table 2. The liquefaction of corn stover was enhanced when the harsh reaction conditions were employed. In particular, the LP yield increased clearly and the yield of the phenolic monomers rose sharply from $9.91 \%$ to $18.47 \%$ when the initial hydrogen pressure changed from $1 \mathrm{MPa}$ to $3 \mathrm{MPa}$. As the pressure was further raised to 4 or $5 \mathrm{MPa}$, the yield remained at a stable level. This suggested that a certain hydrogen pressure had a facilitation effect on the delignification and the depolymerization of lignin because in the reductive depolymerization of lignin, the hydrogenolysis and hydrodeoxygenation reactions are the hydrogen-consuming processes. ${ }^{8}$ In addition, a part of cellulose or/and hemicellulose, particularly those in the amorphous carbohydrate fractions in corn stover, might be methylated and transformed into LP or EP due to methanolysis. ${ }^{38}$ Therefore, the LP and EP yields were beyond the total lignin content in corn stover $(21.10 \%)$ and the SR yield declined under the more harsh conditions.

Together with the effects of the reaction temperature and initial hydrogen pressure, the influences of the dosage of catalyst and the reaction time were also investigated. As summarized in Table 3, the yield of the phenolic monomers was stable at around $18 \%$ with the presence of $\mathrm{MoS}_{2}$ in the reaction. The yield was three times higher than that for the blank reaction, indicating that $\mathrm{MoS}_{2}$ played a positive role in the lignin-first process. The sulfur vacancies in $\mathrm{MoS}_{2}$ could effectively adsorb oxygen in $\beta-\mathrm{O}-4$ and other oxygen-containing linkages, thus accelerating the bond cleavage and leading to the production of monomers. ${ }^{32}$ The monomeric products were stabilized through hydrogenation, ${ }^{23,32}$ which would be proven later by NMR characterization and the analysis of the chemical components of the solid residues. The HDO might be enhanced when the reaction time was prolonged. This phenomenon could be observed from the results displayed in Table 4, with the decline of the yield of the phenolic monomers, as well as in Fig. 3, with the increasing of the EP yield. Moreover, the increase of the LP yield and the decrease of the SR yield suggested the improvement of the liquefaction and the aggravation of the degradation of the carbohydrate components.

\subsection{Characterization of liquid products}

The chemical compositions of the liquid products $\left(250{ }^{\circ} \mathrm{C}\right.$, $3 \mathrm{MPa} \mathrm{H}_{2}, 15 \mathrm{wt} \% \mathrm{MoS}_{2}, 2 \mathrm{~h}$ ) were further characterized by FTIR and ${ }^{1} \mathrm{H}-{ }^{13} \mathrm{C}$ HSQC NMR in order to clarify the structural 
(a)
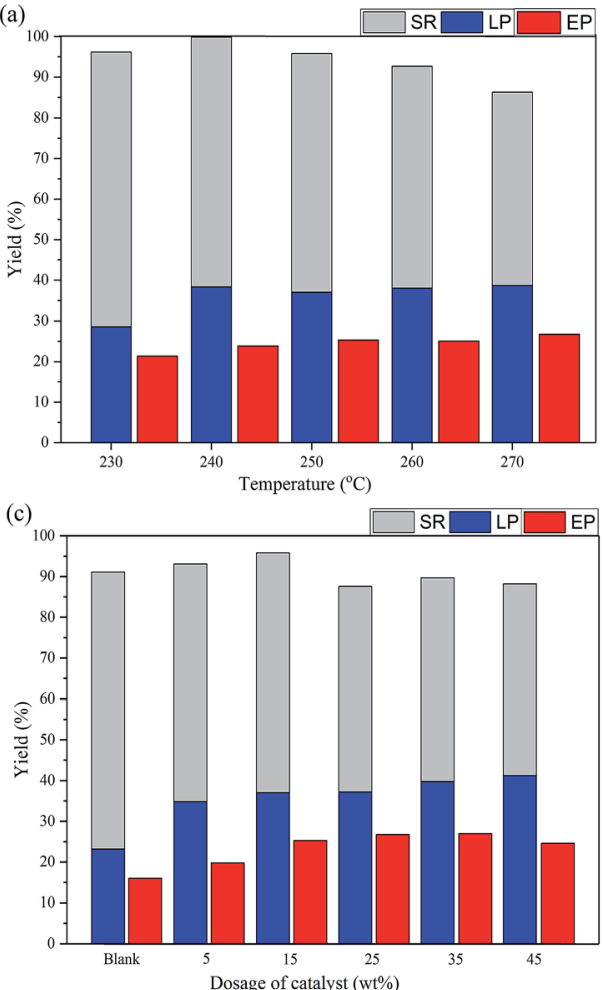

(b)

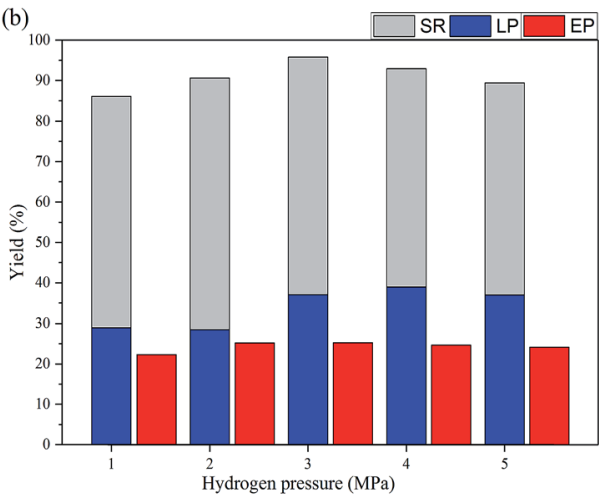

(d)

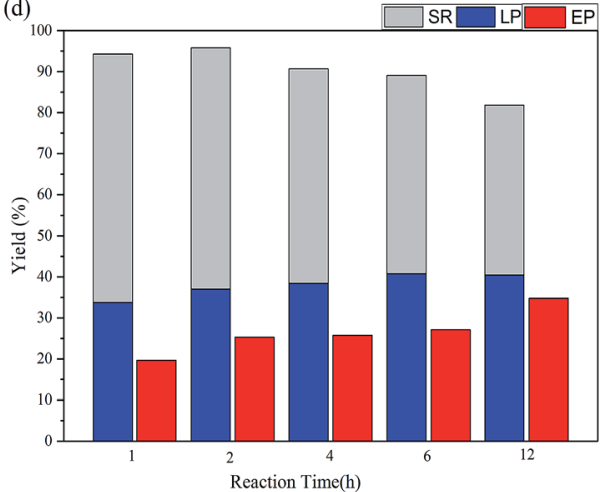

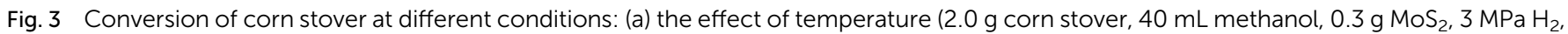
and $2 \mathrm{~h}$ ); (b) the effect of pressure ( $2.0 \mathrm{~g}$ corn stover, $40 \mathrm{~mL}$ methanol, $0.3 \mathrm{~g} \mathrm{MoS}_{2}, 250{ }^{\circ} \mathrm{C}$, and $2 \mathrm{~h}$ ); (c) the effect of the dosage of the catalyst ( $2.0 \mathrm{~g}$ corn stover, $40 \mathrm{~mL}$ methanol, $250^{\circ} \mathrm{C}_{3} 3 \mathrm{MPa} \mathrm{H}_{2}$, and $2 \mathrm{~h}$ ); (d) the effect of the reaction time ( $2.0 \mathrm{~g}$ corn stover, $40 \mathrm{~mL}$ methanol, $0.3 \mathrm{~g} \mathrm{MoS}$, $250{ }^{\circ} \mathrm{C}$, and $3 \mathrm{MPa} \mathrm{H}_{2}$ ) (SR: solid residual corn stover, LP: liquid products, EP: ethyl acetate soluble products).

Table 1 The phenolic monomer yield at different reaction temperatures ${ }^{a}\left({ }^{\circ} \mathrm{C}\right)$

\begin{tabular}{|c|c|c|c|c|c|c|c|c|c|c|c|c|c|c|}
\hline $\begin{array}{l}\text { Reaction } \\
\text { temperature }\left({ }^{\circ} \mathrm{C}\right)\end{array}$ & \multicolumn{14}{|c|}{ Yield of phenolic monomer (\%) } \\
\hline 240 & 2.38 & 1.08 & 0.95 & 2.81 & 1.86 & 0.00 & 0.61 & 3.80 & 2.10 & 1.88 & 7.50 & 4.41 & 4.48 & 17.47 \\
\hline 250 & 2.63 & 0.61 & 1.3 & 3.75 & 1.55 & 1.45 & 0.64 & 3.01 & 2.02 & 1.51 & 8.11 & 3.65 & 6.10 & 18.47 \\
\hline 260 & 3.18 & 0.31 & 1.32 & 3.92 & 1.54 & 2.09 & 0.00 & 3.12 & 2.06 & 1.64 & 8.42 & 3.12 & 7.33 & 19.18 \\
\hline
\end{tabular}

${ }^{a}$ Condition: $2.0 \mathrm{~g}$ corn stover, $40 \mathrm{~mL}$ methanol, $0.3 \mathrm{~g} \mathrm{MoS}_{2}, 3 \mathrm{MPa} \mathrm{H}_{2}$, and $2 \mathrm{~h} .^{b}$ 1: 4-Ethylphenol. ${ }^{c}$ 2:2,3-Dihydrobenzofuran. The calibration factor of an internal standard method was calculated by an effective carbon number (ECN) method explained in the ESI. ${ }^{d}$ 3: 2 -Methoxy-4-ethylphenol. ${ }^{e}$ 4: 2-Methoxy-4-propylphenol. ${ }^{f}$ 5: 2-Methoxy-4-propenylphenol. ${ }^{g}$ 6: Methyl 3-(4-hydroxyphenyl)propionate. The calibration factor of an internal standard method was calculated by an effective carbon number (ECN) method explained in the ESI. ${ }^{h}$ 7: 2 ,6-Dimethoxy-4-allylphenol. ${ }^{i}$ 8: 2,6 Dimethoxy-4-propylphenol. ${ }^{j}$ 9: Methyl trans-p-coumarate. The calibration factor of an internal standard method was calculated by an effective carbon number (ECN) method explained in the ESI. ${ }^{k}$ 10: Methyl trans-4-hydroxy-3-methoxycinnamate.

transformation and get a comprehensive understanding of the lignin-first catalytic depolymerization process.

First, the EP (bio-oil) was rich in the phenolic monomers due to the abundant related functional structure observed in the FTIR spectra shown in Fig. 4. The peak at $3370 \mathrm{~cm}^{-1}$ was attributed to the $\mathrm{O}-\mathrm{H}$ stretching vibration, while the $\mathrm{C}-\mathrm{H}$ symmetric and asymmetric vibrations in methyl and methylene group appeared at 2930 and $2850 \mathrm{~cm}^{-1}$, respectively. ${ }^{39}$ The $1720 \mathrm{~cm}^{-1}$ peak was assigned to the carbonyl stretching related to methyl $p$-coumarate. The strong absorption peak at 1610, 1510, and $1450 \mathrm{~cm}^{-1}$ in the bio-oil products suggested the existence of the benzene structure. The peak at $1360 \mathrm{~cm}^{-1}$ indicated the presence of the alkyl groups due to the $\mathrm{sp}^{3} \mathrm{C}-\mathrm{H}$ bending/rocking; ${ }^{8}$ the peak at $1330 \mathrm{~cm}^{-1}$ was derived from the phenolic $\mathrm{OH}$ (syringyl nuclei) absorptions; the guaiacyl ring breathing with $\mathrm{C}=\mathrm{O}$ stretching appeared at $1270 \mathrm{~cm}^{-1} .{ }^{40}$ The peak at $1210 \mathrm{~cm}^{-1}$ was attributed to the asymmetric vibration of $\mathrm{C}-\mathrm{O}-\mathrm{C}$ in methylated ester. In particular, the peak at $1170 \mathrm{~cm}^{-1}$ was characterized for the ester-linked $p$-hydroxycinnamic acids. ${ }^{\mathbf{4 1}} \mathrm{In}$ addition, the $\mathrm{C}-\mathrm{O}$ stretching in the alkoxy functional group was observed at $1110 \mathrm{~cm}^{-18}$ and the peak at $834 \mathrm{~cm}^{-1}$ was considered to be the signal of the aromatic $\mathrm{C}-\mathrm{H}$ out-of-plane 
Table 2 The phenolic monomer yield at different initial hydrogen pressures ${ }^{a}$ (MPa)

\begin{tabular}{|c|c|c|c|c|c|c|c|c|c|c|c|c|c|c|}
\hline $\begin{array}{l}\text { Initial hydrogen } \\
\text { pressure (MPa) }\end{array}$ & \multicolumn{14}{|c|}{ Yield of phenolic monomer (\%) } \\
\hline 2 & 2.49 & 0.46 & 1.06 & 2.92 & 1.23 & 1.16 & 0.54 & 2.50 & 2.05 & 1.48 & 6.69 & 3.04 & 5.70 & 15.89 \\
\hline 3 & 2.63 & 0.61 & 1.30 & 3.75 & 1.55 & 1.45 & 0.64 & 3.01 & 2.02 & 1.51 & 8.11 & 3.65 & 6.10 & 18.47 \\
\hline 4 & 3.43 & 0.52 & 1.57 & 2.73 & 1.43 & 1.74 & 0.79 & 2.79 & 1.59 & 1.21 & 6.94 & 3.58 & 6.76 & 17.80 \\
\hline
\end{tabular}

${ }^{a}$ Condition: $2.0 \mathrm{~g}$ corn stover, $40 \mathrm{~mL}$ methanol, $0.3 \mathrm{~g} \mathrm{MoS}, 250{ }^{\circ} \mathrm{C}$, and $2 \mathrm{~h} .^{b}$ 1: 4-Ethylphenol. ${ }^{c}$ 2:2,3-Dihydrobenzofuran. The calibration factor of an internal standard method was calculated by an effective carbon number (ECN) method explained in the ESI. ${ }^{d}$ 3: 2-Methoxy-4-ethylphenol. ${ }^{e}$ 4: 2 Methoxy-4-propylphenol. ${ }^{f}$ 5: 2-Methoxy-4-propenylphenol. ${ }^{g}$ 6: Methyl 3-(4-hydroxyphenyl)propionate. The calibration factor of an internal standard method was calculated by an effective carbon number (ECN) method explained in the ESI. ${ }^{h}$ 7: 2,6-Dimethoxy-4-allylphenol. ${ }^{i}$ 8: 2,6 Dimethoxy-4-propylphenol. ${ }^{j}$ 9: Methyl trans-p-coumarate. The calibration factor of an internal standard method was calculated by an effective carbon number (ECN) method explained in the ESI. ${ }^{k}$ 10: Methyl trans-4-hydroxy-3-methoxycinnamate.

Table 3 The phenolic monomer yield at different dosages of catalyst ${ }^{a}(\mathrm{wt} \%)$

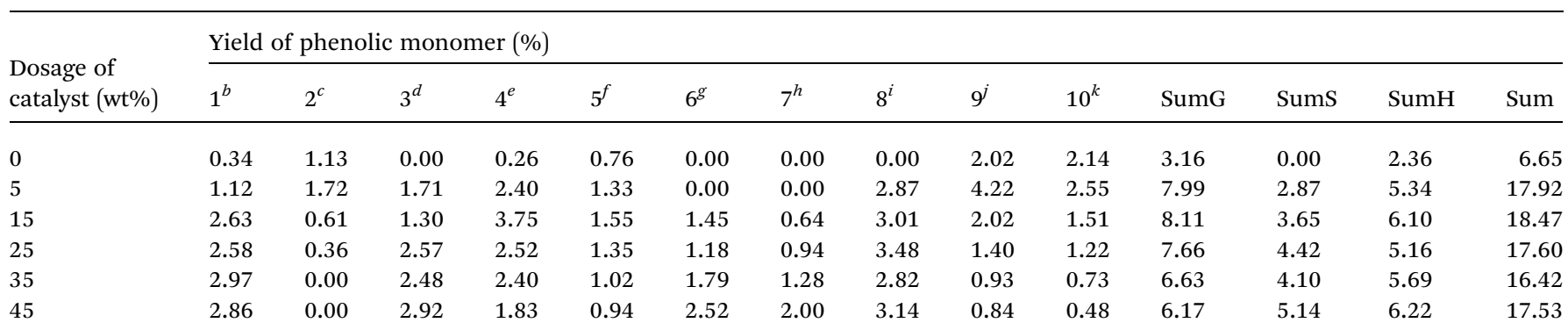

${ }^{a}$ Condition: $2.0 \mathrm{~g}$ corn stover, $40 \mathrm{~mL}$ methanol, $250{ }^{\circ} \mathrm{C}, 3 \mathrm{MPa} \mathrm{H}_{2}$, and 2 h. ${ }^{b}$ 1: 4-Ethylphenol. ${ }^{c}$ 2: 2,3-Dihydrobenzofuran. The calibration factor of an internal standard method was calculated by an effective carbon number (ECN) method explained in the ESI. ${ }^{d}$ 3: 2-Methoxy-4-ethylphenol. ${ }^{e} 4: 2$ Methoxy-4-propylphenol. ${ }^{f}$ 5: 2-Methoxy-4-propenylphenol. ${ }^{g}$ 6: Methyl 3-(4-hydroxyphenyl)propionate. The calibration factor of an internal standard method was calculated by an effective carbon number (ECN) method explained in the ESI. ${ }^{h}$ 7: 2,6-Dimethoxy-4-allylphenol. ${ }^{i}$ 8: 2 ,6Dimethoxy-4-propylphenol. ${ }^{j}$ 9: Methyl trans-p-coumarate. The calibration factor of an internal standard method was calculated by an effective carbon number (ECN) method explained in the ESI. ${ }^{k}$ 10: Methyl trans-4-hydroxy-3-methoxycinnamate.

deformation. ${ }^{39}$ Moreover, carbohydrates were considered to be present in the ethyl acetate insoluble products because the phenolic absorptions, particularly the peaks corresponding to the benzene and alkoxyl functional structures, were weak or even faded, but $\mathrm{O}-\mathrm{H}$ stretching at the $\beta$-glucosidic linkages was observed at $1195 \mathrm{~cm}^{-1} \cdot{ }^{42}$ According to the FT-IR spectra, it was suggested that the liquid products of the depolymerization of native corn stover lignin were divided into two parts: one was the EP bio-oil rich of the lignin-degraded aromatic structures, including the phenolic monomers and oligomers, while the other was the ethyl acetate insoluble products mostly composed of polysaccharides. To further investigate the structure of the liquid products, ${ }^{1} \mathrm{H}-{ }^{13} \mathrm{C}$ HSQC NMR was also conducted.

Table 4 The phenolic monomer yield at different reaction times $^{a}(\mathrm{~h})$

\begin{tabular}{|c|c|c|c|c|c|c|c|c|c|c|c|c|c|c|}
\hline $\begin{array}{l}\text { Reaction } \\
\text { time (h) }\end{array}$ & $1^{b}$ & $2^{c}$ & $3^{d}$ & $4^{e}$ & $5^{f}$ & $6^{g}$ & $7^{h}$ & $8^{i}$ & $9^{j}$ & $10^{k}$ & SumG & Sums & SumH & Sum \\
\hline 2 & 2.63 & 0.61 & 1.30 & 3.75 & 1.55 & 1.45 & 0.64 & 3.01 & 2.02 & 1.51 & 8.11 & 3.65 & 6.10 & 18.47 \\
\hline 4 & 2.25 & 0.00 & 2.52 & 2.02 & 1.40 & 0.87 & 0.69 & 2.99 & 1.57 & 1.39 & 7.33 & 3.68 & 4.69 & 15.70 \\
\hline 6 & 2.45 & 0.44 & 2.82 & 1.54 & 1.19 & 0.00 & 0.00 & 2.56 & 1.24 & 1.36 & 6.91 & 2.56 & 3.69 & 13.60 \\
\hline
\end{tabular}

${ }^{a}$ Condition: $2.0 \mathrm{~g}$ corn stover, $40 \mathrm{~mL}$ methanol, $0.3 \mathrm{~g} \mathrm{MoS}_{2}, 250{ }^{\circ} \mathrm{C}$, and $3 \mathrm{MPa} \mathrm{H}_{2} \cdot{ }^{b}$ 1: 4-Ethylphenol. ${ }^{c}$ 2: 2,3-Dihydrobenzofuran. The calibration factor of an internal standard method was calculated by an effective carbon number (ECN) method explained in the ESI. ${ }^{d} 3$ : 2 -Methoxy-4ethylphenol. ${ }^{e}$ 4: 2-Methoxy-4-propylphenol. ${ }^{f}$ 5: 2-Methoxy-4-propenylphenol. ${ }^{g}$ 6: Methyl 3-(4-hydroxyphenyl)propionate. The calibration factor of an internal standard method was calculated by an effective carbon number (ECN) method explained in the ESI. ${ }^{h}$ 7: 2,6 -Dimethoxy-4-allylphenol. ${ }^{i}$ 8: 2,6-Dimethoxy-4-propylphenol. ${ }^{j}$ 9: Methyl trans-p-coumarate. The calibration factor of an internal standard method was calculated by an effective carbon number (ECN) method explained in the ESI. ${ }^{k}$ 10: Methyl trans-4-hydroxy-3-methoxycinnamate. 


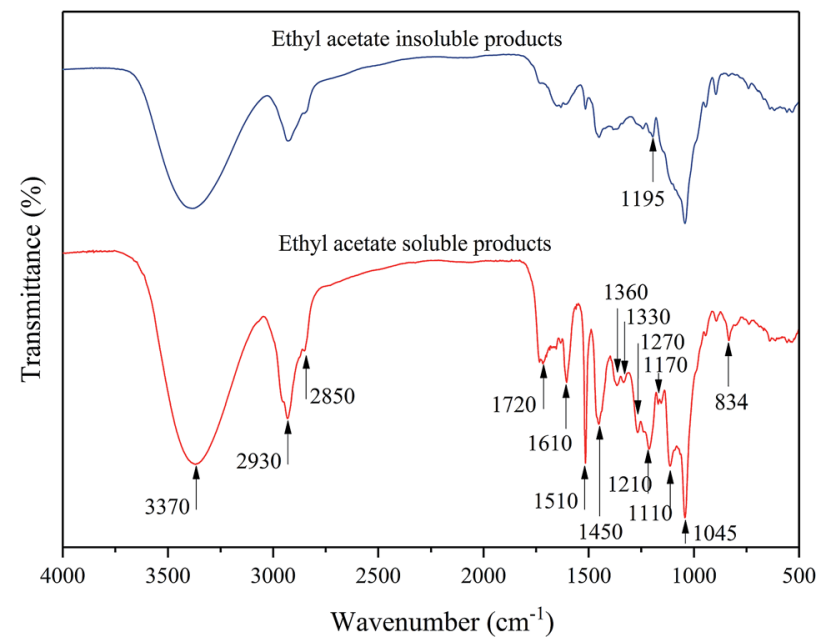

Fig. 4 FT-IR spectra of the ethyl acetate soluble and insoluble products.

The information of the chemical structural linkage of the liquid products was explained by the signals originated from the parts of the type-linkages of the lignin-carbohydrate complexes and the representative lignin monomer units in ${ }^{1} \mathrm{H}-{ }^{13} \mathrm{C}$ HSQC NMR (Fig. 5a and b for EP and Fig. 5c for the ethyl acetate-insoluble products). Four inter-linkages of lignin in the extractive-free corn stover ( $\beta$-O-4 (53-60\%), $\beta-5$ (27-29\%), $\beta$ $\beta(10-11 \%)$, and $\beta-1(3-7 \%))$ were observed as reported earlier. ${ }^{43}$ First, the cleavage of the $\beta-\mathrm{O}-4$ linkages occurred in the ligninfirst process, which could be observed in the ${ }^{1} \mathrm{H}^{-}{ }^{13} \mathrm{C}$ HSQC NMR characterization of liquid products with $\mathrm{MoS}_{2}$ catalysts, including ethyl acetate soluble products and ethyl acetate insoluble products as shown in Fig. 5a and c. Moreover, the yield of the phenolic monomers was much higher with the presence of $\mathrm{MoS}_{2}$ (Table 3, line 3) than that in the blank (Table 3 , line 1). This suggested that the monomeric products were stabilized by $\mathrm{MoS}_{2}$ through hydrogenation, which was consistent with the previous study. ${ }^{23}$ For instance, the contours of the major linkages of $\beta-\mathrm{O}-4$, including the signals of $\mathrm{C}_{\alpha}-\mathrm{H}_{\alpha}\left(\delta_{\mathrm{C}} / \delta_{\mathrm{H}}\right.$, 72.9/4.30 ppm and 62.9/4.31 ppm for the $\gamma$-acylated lignin units), $\mathrm{C}_{\beta}-\mathrm{H}_{\beta}\left(\delta_{\mathrm{C}} / \delta_{\mathrm{H}}, 83.6 / 4.40 \mathrm{ppm}\right.$ for $\mathrm{G} / \mathrm{S}$ type and $86.3 / 4.10$ for $\mathrm{S} / \mathrm{S}$ type), and $\mathrm{C}_{\gamma}-\mathrm{H}_{\gamma}\left(\delta_{\mathrm{C}} / \delta_{\mathrm{H}}, 60.5 / 3.50 \mathrm{ppm}\right)$, disappeared after the catalytic process. ${ }^{\mathbf{4 2 , 4 4}}$ Hence, it was concluded that the $\beta-\mathrm{O}-4$ linkages of the lignin fragments in the reaction had been severely broken. Moreover, the cleavage of the G/S and S/S type $\beta-O-4$ linkages could be responsible for the partial generation of the phenolic monomers. In addition, it was reported that the hydroxycinnamic acid moieties of corn lignin, including about $18 \% p$-coumaric acid (pCA) and 3-4\% ferulic acid (FA), were deposited on the cell wall of corn stover and linked through the ester and ether linkages. ${ }^{27,45}$ The $\gamma$-ester of LCCs present the contours at $\delta_{\mathrm{C}} / \delta_{\mathrm{H}} 62-64 / 4.0-4.25 \mathrm{ppm}$. The benzyl ether structures between the lignin units and carbohydrates showed the signals at $\delta_{\mathrm{C}} / \delta_{\mathrm{H}} 80-81 / 4.4-4.6 \mathrm{ppm}$ and 80-81/5.0-5.2 ppm. $^{43}$ Both ester and ether linkages were not found in the liquid products. Therefore, the formation of MpC and MF monomers could be related to the cleavage of the ester and ether bonds.

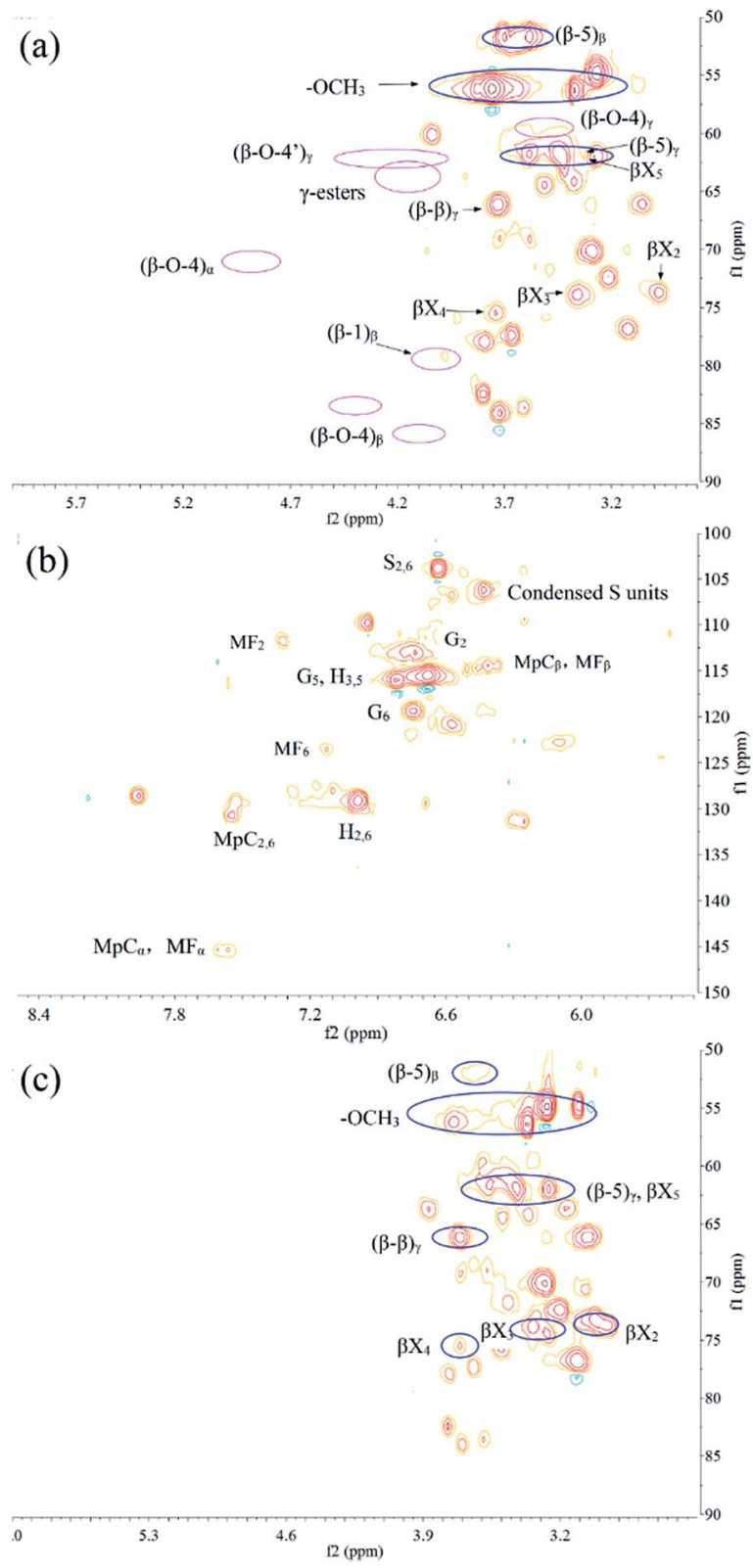

Fig. $5{ }^{1} \mathrm{H}-{ }^{13} \mathrm{C}$ HSQC-NMR spectra of the liquid products: (a), (b) ethyl acetate soluble products, and (c) ethyl acetate insoluble products (the detailed typical structure refer to Fig. S1 $\uparrow$ ).

Moreover, the primary linkages retained in the liquid products were considered to be the $\beta-5$ linkages and the $\beta-\beta$ linkages because $\mathrm{C}_{\beta}-\mathrm{H}_{\beta}$ and $\mathrm{C}_{\gamma}-\mathrm{H}_{\gamma}$, correlated to the $\beta-5$ linkages, were distinguished at $\delta_{\mathrm{C}} / \delta_{\mathrm{H}} 51.8 / 3.58 \mathrm{ppm}$ and 61.6/3.43 ppm, respectively, and the signals for $\mathrm{C}_{\gamma}-\mathrm{H}_{\gamma}$ in the $\beta$ - $\beta$ linkages were located at $\delta_{\mathrm{C}} / \delta_{\mathrm{H}} 66.1 / 3.73 \mathrm{ppm} .{ }^{43}$ Moreover, there was only a trace of the $\beta-1$ linkages that was observed at $\delta_{\mathrm{C}} / \delta_{\mathrm{H}} 79.1 /$ 3.97 ppm assigned to the $\mathrm{C}_{\beta}-\mathrm{H}_{\beta}$ signals due to its relatively low content in the raw materials. ${ }^{43}$ Moreover, other types of the LCCs linkages and phenyl glycoside linkages were detected at $\delta_{\mathrm{C}} / \delta_{\mathrm{H}} 100.4 / 4.51 \mathrm{ppm}$ and $102.7 / 4.63 \mathrm{ppm}$, respectively, ${ }^{46}$ and $\beta$ D-xylopyranoside $(\beta \mathrm{X})$ presented the contours at $\delta_{\mathrm{C}} / \delta_{\mathrm{H}} 102.2 /$ 4.24 ppm, 73.6/2.98 ppm, 73.9/3.35 ppm, 75.5/3.74 ppm, and $61.6 / 3.43 \mathrm{ppm}$, which referred to the $\mathrm{C}_{1}-\mathrm{H}_{1}, \mathrm{C}_{2}-\mathrm{H}_{2}, \mathrm{C}_{3}-\mathrm{H}_{3}, \mathrm{C}_{4}-$ 
$\mathrm{H}_{4}$, and $\mathrm{C}_{5}-\mathrm{H}_{5}$, respectively. The signals related to carbohydrates indicated that there were carbohydrates reserved in LP together with lignin oligomers. The results also confirmed the previous discussion that not only lignin but also the carbohydrate components were liquefied.

In the aromatic regions of the ${ }^{1} \mathrm{H}^{-13} \mathrm{C}$ HSQC NMR spectra of EP (Fig. 5b), different lignin units (G, S, and $H$ type) of the phenolic units are clearly shown. The spectra of the ethyl acetate-insoluble products are blank, suggesting that the phenolic components were absent. $\mathrm{C}_{2,6}-\mathrm{H}_{2,6}$ and $\mathrm{C}_{3,5}-\mathrm{H}_{3,5}$ correlated to the $\mathrm{H}$ units at $\delta_{\mathrm{C}} / \delta_{\mathrm{H}} 128.9 / 6.99 \mathrm{ppm}$ and 115.5/ $6.68 \mathrm{ppm}$, respectively. In particular, $\mathrm{MpC}$ showed the signals for $\mathrm{C}_{2,6}-\mathrm{H}_{2,6}, \mathrm{C}_{\alpha}-\mathrm{H}_{\alpha}$, and $\mathrm{C}_{\beta}-\mathrm{H}_{\beta}$ at $\delta_{\mathrm{C}} / \delta_{\mathrm{H}} 130.7 / 7.54 \mathrm{ppm}, 145.4 /$ $7.56 \mathrm{ppm}$, and $114.4 / 6.41 \mathrm{ppm}$, respectively. $\mathrm{C}_{2}-\mathrm{H}_{2}$ and $\mathrm{C}_{6}-\mathrm{H}_{6}$ in the $\mathrm{G}$ units were observed at $\delta_{\mathrm{C}} / \delta_{\mathrm{H}} 113.2 / 6.73 \mathrm{ppm}$ and $119.3 /$ $6.74 \mathrm{ppm}$, respectively. $\mathrm{C}_{2}-\mathrm{H}_{2}$ and $\mathrm{C}_{6}-\mathrm{H}_{6}$ correlated to $\mathrm{MF}$ at $\delta_{\mathrm{C}} /$ $\delta_{\mathrm{H}}$ 111.8/7.23 ppm and 123.5/7.13 ppm, respectively, while the signals of $\mathrm{C}_{\alpha}-\mathrm{H}_{\alpha}$ and $\mathrm{C}_{\beta}-\mathrm{H}_{\beta}$ in MF were overlapped with those of MpC. The $\mathrm{S}$ units related to $\mathrm{C}_{2,6}-\mathrm{H}_{2,6}$ displayed contours at $\delta_{\mathrm{C}} / \delta_{\mathrm{H}} 103.7 / 6.63 \mathrm{ppm}$ and the condensed $\mathrm{S}$ units of oligomers showed contours at $\delta_{\mathrm{C}} / \delta_{\mathrm{H}} 106.0 / 6.43 \mathrm{ppm}$. The characterization of the aromatic regions supported the FT-IR spectra results, which suggested that the EP was rich in the phenolic monomers and oligomers. It was also in good agreement with the previous reports. ${ }^{43,44,46}$

\subsection{Chemical components analysis of solid residues and liquid products}

Typically, corn stover $(2.0 \mathrm{~g}), \mathrm{MoS}_{2}(0.3 \mathrm{~g})$, and methanol (40 mL) were mixed and $\mathrm{H}_{2}$ was purged into the mixture at $3 \mathrm{MPa}$. The reaction was carried out at $250{ }^{\circ} \mathrm{C}$ for $2 \mathrm{~h}$. The solid residues and the liquid products were further analysed. First, the determination of the solid residue suggested that, based on the corn stover feedstocks before the reaction, $90.31 \%$ glucan, $45.44 \%$ xylan, and $25.65 \%$ lignin were reserved in the residues, indicating that almost all of the glucan and about half of the xylan were reserved in the solid residues, while about $75 \%$ lignin was dissolved in methanol and depolymerized into the fragments, such as monomers and oligomers. In contrast, $76.91 \%$ glucan, $67.20 \%$ xylan, and $46.86 \%$ lignin were reserved in the solid residues at the same condition in the blank reaction. Considering the cleavage of the $\beta-\mathrm{O}-4$ linkages observed in the ${ }^{1} \mathrm{H}^{-13} \mathrm{C}$ HSQC NMR, it was concluded that the $\mathrm{MoS}_{2}$ catalyst promoted the delignification and aggravated the degradation of amorphous xylan at the same time. However, compared with the blank reaction, the reaction with $\mathrm{MoS}_{2}$ produced higher glucan content in the solid residues, which was interesting and perplexing. To figure out the loss of carbohydrates in the presence of $\mathrm{MoS}_{2}$, particularly xylan, the liquid products were extracted with water after the solvent was removed. Surprisingly, no monomeric carbohydrates were detected. Hence, EP and the ethyl acetate-insoluble products were collected and hydrolyzed by $4 \mathrm{wt} \% \mathrm{H}_{2} \mathrm{SO}_{4}$ at $120{ }^{\circ} \mathrm{C}$ for $60 \mathrm{~min}$ and $13.41 \%$ and $17.42 \%$ xylan, respectively, were detected. These results suggested that some of the liquefied xylan could be methylated. Moreover, some of the methylated xylan with a strong molecular polarity was insoluble in ethyl acetate, while the rest might be further subjected to side reactions due to the abundance of active hydroxyl groups and high temperature. The distribution of acid hydrolyzed xylan in LP was also consistent with the contours of the $\beta$-X chemical bonds in the ${ }^{1} \mathrm{H}^{1}{ }^{13} \mathrm{C}$ HSQC NMR spectra.

\subsection{Model compounds reactions and potential mechanism}

To figure out the potential mechanism of the generation of phenolic monomers, the high-content hydroxycinnamic acid moieties, including pCA and FA, in corn stover were used in the model reaction. The product yield was calculated by mole yield. First, $17.58 \%$ 4-ethylphenol and $14.85 \%$ MpC were produced after the model pCA reacted for $2 \mathrm{~h}$ and the mole yield respectively increased to $39.55 \%$ and decreased to $5.98 \%$ when the reaction time prolonged to $6 \mathrm{~h}$. Second, 20.42\% 2-methoxy-4ethylphenol and $11.57 \%$ MF was generated when FA was used in the model reaction for $2 \mathrm{~h}$. Similarly, $23.97 \%$ and $1.09 \%$ mole yield was respectively reached after $6 \mathrm{~h}$, which proved the increase of the yield of 4-ethylphenol and 2-methoxy-4ethylphenol in the lignin-first process of corn stover when the harsh reaction conditions were chosen as summarized in Tables 3 and 4 .

Collectively, the potential mechanism can be explained in Fig. 6. In the lignin-first process, the native corn stover lignin can be partially dissolved in supercritical methanol together with amorphous xylan and the dissolving limitation can be promoted by a $\mathrm{MoS}_{2}$ catalyst through the cleavage of the $\beta-\mathrm{O}-4$, $\gamma$-ester, and benzyl ether linkages, resulting in the release of pCA and FA monomer. Moreover, the dissolved lignin fragments will be further subjected to a hydrocracking reaction to be depolymerized into the phenolic monomers with $\mathrm{MoS}_{2}$. In particular, the hydroxycinnamic acid moieties (mainly pCA and FA) can further transform into 4-ethylphenol, 2-methoxy-4ethylphenol, and methyl esters. Moreover, the 2-methoxy-4propylphenol production can be assigned to the hydrogenation of 2-methoxy-4-propenylphenol, while the other products can be released from the cleavage of the $\mathrm{G} / \mathrm{S}$ and $\mathrm{S} / \mathrm{S}$ type $\beta-\mathrm{O}-4$ linkages in native lignin. ${ }^{24}$

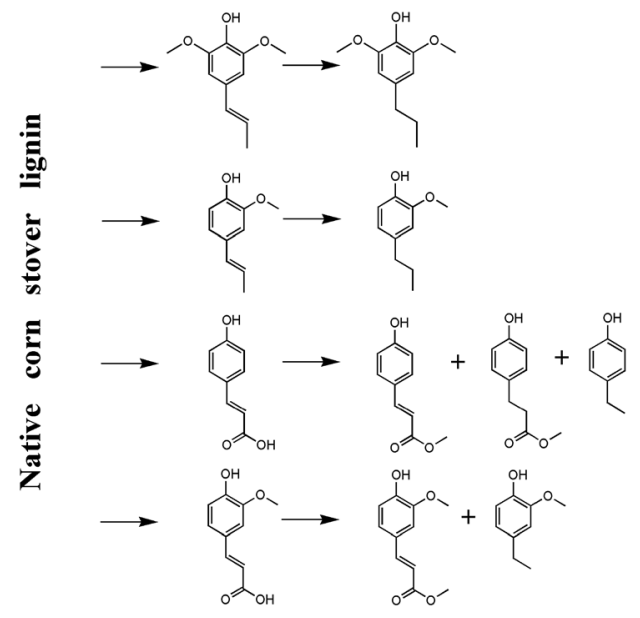

Fig. 6 The potential mechanism of the native corn stover lignin depolymerization. 


\subsection{Catalyst recycling}

After the catalytic depolymerization reaction of corn stover, the residues were washed by adding water and filtered through a 100-mesh screen for several times. The filtrate containing $\mathrm{MoS}_{2}$ was collected by vacuum filtering and drying. The monomer yield decreased from $18.47 \%$ to $15.97 \%$ at the second use of the catalyst and dropped to $14.30 \%$ at the fifth reaction as summarized in Table S2. $\uparrow$ Therefore, $\mathrm{MoS}_{2}$ was considered to be relatively effective for the depolymerization of native corn stover lignin. The fading of the (001) and (110) diffraction planes as shown in the XRD spectra (Fig. 1a) and the increase of the oxygen content detected by XPS together with the loss of the acidity of the recycled $\mathrm{MoS}_{2}$ after five times (Fig. S2 $\dagger$ ) could be responsible for the partial decline of the phenolic monomer yield.

\section{Conclusion}

The non-noble metal catalyst $\mathrm{MoS}_{2}$ played a positive role in the depolymerization of native corn stover lignin by lignin-first biorefinery. The yield of the phenolic monomers was enhanced from $6.65 \%$ to $18.47 \%$ with the $\mathrm{MoS}_{2}$ catalyst at $250{ }^{\circ} \mathrm{C}$ in supercritical methanol. About $75 \%$ lignin was degraded due to the cleavage of the $\beta$-O- $4, \gamma$-ester, and benzyl ether linkages with more than $90 \%$ glucan reserved in the solid residues. It has been proposed that the depolymerization of the hydroxycinnamic acid moieties primarily produces some phenolic monomers, such as 4-ethylphenol and 2-methoxy-4ethylphenol as well as the methyl esters. The $\mathrm{MoS}_{2}$ catalyst still exhibited a relatively effective performance with $14.30 \%$ phenolic monomer yield after the fifth run.

\section{Conflicts of interest}

There are no conflicts to declare.

\section{Acknowledgements}

This study was financially supported by the Program of National Natural Science Foundation of China (51476178 and 51536009), the National Key Technology R\&D Program of China (No. 2015BAD15B06).

\section{References}

1 T. E. Amidon and S. Liu, Biotechnol. Adv., 2009, 27, 542-550. 2 C. Li, X. Zhao, A. Wang, G. W. Huber and T. Zhang, Chem. Rev., 2015, 115, 11559-11624.

3 T. Renders, S. Van den Bosch, S. F. Koelewijn, W. Schutyser and B. F. Sels, Energy Environ. Sci., 2017, 10, 1551-1557.

4 J. Zakzeski, P. C. A. Bruijnincx, A. L. Jongerius and B. M. Weckhuysen, Chem. Rev., 2010, 110, 3552-3599.

5 M. Kleinert and T. Barth, Energy Fuels, 2008, 22, 1371-1379.

6 C. O. Tuck, E. Pérez, I. T. Horváth, R. A. Sheldon and M. Poliakoff, Science, 2012, 337, 695-699.
7 E. Sjöström and R. Alén, Analytical methods in wood chemistry, pulping, and papermaking, Springer Science \& Business Media, 2013.

8 R. Shu, J. Long, Y. Xu, L. Ma, Q. Zhang, T. Wang, C. Wang, Z. Yuan and Q. Wu, Bioresour. Technol., 2016, 200, 14-22.

9 J. Wang, W. Li, H. Wang, Q. Ma, S. Li, H.-m. Chang and H. Jameel, Bioresour. Technol., 2017, 243, 100-106.

10 R. Shu, J. Long, Z. Yuan, Q. Zhang, T. Wang, C. Wang and L. Ma, Bioresour. Technol., 2015, 179, 84-90.

11 J. Yang, L. Zhao, S. T. Liu, Y. Y. Wang and L. Y. Dai, Bioresour. Technol., 2016, 212, 302-310.

$12 \mathrm{~W} . \mathrm{Xu}, \mathrm{S} . \mathrm{J}$. Miller, P. K. Agrawal and C. W. Jones, ChemSusChem, 2012, 5, 667-675.

13 L. Chen, T. I. Koranyi and E. J. M. Hensen, Chem. Commun., 2016, 52, 9375-9378.

14 J. Horacek, F. Homola, I. Kubickova and D. Kubicka, Catal. Today, 2012, 179, 191-198.

15 C. R. Kumar, N. Anand, A. Kloekhorst, C. Cannilla, G. Bonura, F. Frusteri, K. Barta and H. J. Heeres, Green Chem., 2015, 17, 4921-4930.

$16 \mathrm{C} . \mathrm{Xu}$ and F. Ferdosian, Conversion of Lignin into Bio-Based Chemicals and Materials, Springer, 2017.

17 L. Shuai, M. T. Amiri, Y. M. Questell-Santiago, F. Héroguel, Y. Li, H. Kim, R. Meilan, C. Chapple, J. Ralph and J. S. Luterbacher, Science, 2016, 354, 329-333.

18 W. Schutyser, S. Van den Bosch, T. Renders, T. De Boe, S. F. Koelewijn, A. Dewaele, T. Ennaert, O. Verkinderen, B. Goderis, C. M. Courtin and B. F. Sels, Green Chem., 2015, 17, 5035-5045.

19 Q. Song, F. Wang, J. Cai, Y. Wang, J. Zhang, W. Yu and J. Xu, Energy Environ. Sci., 2013, 6, 994-1007.

20 S. Van den Bosch, W. Schutyser, R. Vanholme, T. Driessen, S. F. Koelewijn, T. Renders, B. De Meester, W. J. J. Huijgen, W. Dehaen, C. M. Courtin, B. Lagrain, W. Boerjan and B. F. Sels, Energy Environ. Sci., 2015, 8, 1748-1763.

21 N. Yan, C. Zhao, P. J. Dyson, C. Wang, L.-t. Liu and Y. Kou, ChemSusChem, 2008, 1, 626-629.

22 X. Huang, O. M. Morales Gonzalez, J. Zhu, T. I. Koranyi, M. D. Boot and E. J. M. Hensen, Green Chem., 2017, 19, 175-187.

23 S. Van den Bosch, T. Renders, S. Kennis, S. F. Koelewijn, G. Van den Bossche, T. Vangeel, A. Deneyer, D. Depuydt, C. M. Courtin, J. M. Thevelein, W. Schutyser and B. F. Sels, Green Chem., 2017, 19, 3313-3326.

24 E. M. Anderson, R. Katahira, M. Reed, M. G. Resch, E. M. Karp, G. T. Beckham and Y. Román-Leshkov, ACS Sustainable Chem. Eng., 2016, 4, 6940-6950.

25 X. Huang, X. Ouyang, B. S. Hendriks, O. M. M. Gonzalez, J. Zhu, T. I. Koranyi, M. D. Boot and E. J. M. Hensen, Faraday Discuss., 2017, 202, 141-156.

26 F. Lu and J. Ralph, J. Agric. Food Chem., 1999, 47, 1988-1992. 27 R. Sun, X. F. Sun, S. Q. Wang, W. Zhu and X. Y. Wang, Ind. Crops Prod., 2002, 15, 179-188.

28 J. Geboers, S. Van de Vyver, K. Carpentier, K. de Blochouse, P. Jacobs and B. Sels, Chem. Commun., 2010, 46, 3577-3579. 29 A. Wang and T. Zhang, Acc. Chem. Res., 2013, 46, 1377-1386. 
30 M. Chhowalla, H. S. Shin, G. Eda, L.-J. Li, K. P. Loh and H. Zhang, Nat. Chem., 2013, 5, 263-275.

31 B. Yoosuk, J. H. Kim, C. Song, C. Ngamcharussrivichai and P. Prasassarakich, Catal. Today, 2008, 130, 14-23.

32 C. Zhang, J. Lu, X. Zhang, K. MacArthur, M. Heggen, H. Li and F. Wang, Green Chem., 2016, 18, 6545-6555.

33 N. Li, L. Wei, R. bibi, L. Chen, J. Liu, L. Zhang, Y. Zheng and J. Zhou, Fuel, 2016, 185, 532-540.

34 W. Wang, L. Li, K. Wu, G. Zhu, S. Tan, W. Li and Y. Yang, $R S C$ Adv., 2015, 5, 61799-61807.

35 Q. Liu, W. Li, Q. Ma, S. An, M. Li, H. Jameel and H.-m. Chang, Bioresour. Technol., 2016, 211, 435-442.

36 M. M. Jensen, R. B. Madsen, J. Becker, B. B. Iversen and M. Glasius, J. Anal. Appl. Pyrolysis, 2017, 126, 371-379.

37 J. Li, G. Henriksson and G. Gellerstedt, Bioresour. Technol., 2007, 98, 3061-3068.

38 Y. Ishikawa and S. Saka, Cellulose, 2001, 8, 189-195.
39 S.-N. Sun, M.-F. Li, T.-Q. Yuan, F. Xu and R.-C. Sun, Ind. Crops Prod., 2012, 37, 51-60.

40 N. Kobayashi, N. Okada, A. Hirakawa, T. Sato, J. Kobayashi, S. Hatano, Y. Itaya and S. Mori, Ind. Eng. Chem. Res., 2008, 48, 373-379.

41 C. Jose, A. Gutiérrez, I. M. Rodríguez, D. Ibarra and A. T. Martinez, J. Anal. Appl. Pyrolysis, 2007, 79, 39-46.

42 S. Yang, Y. Zhang, W. Yue, W. Wang, Y.-Y. Wang, T.-Q. Yuan and R.-C. Sun, Biotechnol. Biofuels, 2016, 9, 238.

43 D. Y. Min, H. Jameel, H. M. Chang, L. Lucia, Z. G. Wang and Y. C. Jin, $R S C A d v$. , 2014, 4, 10845-10850.

44 C. Peng, Q. Chen, H. Guo, G. Hu, C. Li, J. Wen, H. Wang, T. Zhang, Z. K. Zhao, R. Sun and H. Xie, ChemCatChem, 2017, 9, 1135-1143.

45 J. Ralph, Phytochem. Rev., 2010, 9, 65-83.

46 S. Yang, T.-Q. Yuan and R.-C. Sun, ACS Sustainable Chem. Eng., 2016, 4, 1006-1015. 